\title{
Increases in Use of Psychiatric Sick Leave During the COVID-19 Pandemic by Healthcare Workers in a Municipality of Argentina. Observed Versus Expected Cases in 2020 compared to Historical data.
}

Agustina M Marconi ( $\square$ agusmar74@gmail.com )

UW Madison: University of Wisconsin Madison https://orcid.org/0000-0002-2560-3030

Ursula S Myers

Medical University of South Carolina

Alfredo M Retamar

Occupational Medicine Direction. Vicente Lopez

Ivanna Jazmin Freddi

Latinas in Global Health

Rafael Zamora

MEDICUS

\section{Research}

Keywords: Pandemic, Mental Health, Health workers, Gender differences

Posted Date: June 11th, 2021

DOl: https://doi.org/10.21203/rs.3.rs-594640/v1

License: (c) (1) This work is licensed under a Creative Commons Attribution 4.0 International License. Read Full License 


\section{Abstract}

Background: The severe respiratory syndrome caused by the novel coronavirus (SARS CoV 2) has caused world-wide pressure on the healthcare workers attempting to treat millions of individuals ill with COVID19, in addition to their regular duties. Aims: examine the use of psychiatric leave by Argentinian healthcare workers during the COVID-19 pandemic; explore differences by gender.

Methods: analysis of "excess of psychiatric sick leave" in health workers at a municipal level for Buenos Aires, January- October 2020. We used historical cases of psychiatric sick leave (2015-2019) and those requested in 2020. The differences between gender were determined using difference in proportions among groups.

Results: The excess of psychiatric sick leave in 2020 compared to historical data was $161.90 \%$. The difference in proportion per sex showed a significant $59.34 \%$ towards female.

Conclusions: healthcare workers in the Argentinian municipality of Vicente Lopez used significantly higher number of psychiatric sick leaves during pandemic. The higher rates of psychiatric sick leave used by female replicate findings of higher rates of psychological symptoms in female healthcare workers.

\section{Introduction}

The COVID-19 pandemic is the greatest global health crisis since the H1N1 influenza pandemic in the early twentieth century. In addition to direct health issues related to the viruses,

Historically, outbreaks such as the Ebola Virus Disease or the Middle East Respiratory Syndrome lead to widespread anxiety, panic, and depression. Given the higher risk of exposure to the pathogen, shortages of equipment, extended workload and being involved in making emotional and ethical decisions, frontline and essential workers such as healthcare workers face increased stress, burnout, depression, and posttraumatic stress disorder (PTSD).

The severe respiratory syndrome caused by the novel coronavirus (SARS CoV 2) has caused world-wide pressure on the healthcare workers attempting to treat millions of individuals ill with COVID-19, in addition to their regular duties. As COVID-19 cases surge in a small periods of time, in addition to the struggles felt universally such as worries about pre-existing health conditions and childcare issues, healthcare workers also faced job-specific stressors including shortages of personal protective equipment, overwhelmed hospitals, lack effective treatment, and having to decide who receives care and who does not. This can result in healthcare workers operating in ways that go against their personal and/or professional moral or ethical code, causing moral injury which in turn leads to increased psychological distress.

Accordingly, a number of studies have found increased levels of anxiety and depression amongst their healthcare workers during the COVID-19 pandemic. A study conducted among medical staff in a tertiary 
infectious disease hospital in China showed a high incidence of anxiety $(23.04 \%)$ and stress disorders (27.39\%). In Italy it has been reported the psychological pressure faced by healthcare frontline workers has resulted in suffering from anxiety and depression as well. Compared to non-medical workers, Zhang and colleagues found higher prevalence of depression, anxiety, insomnia among healthcare workers. A recent systematic review highlights some of the symptoms healthcare workers experienced during the pandemic months: $37.8 \%$ psychological distress $(95 \% \mathrm{Cl}=28.4-48.2 \%), 34.4 \%$ burnout $(95 \% \mathrm{Cl}=19.3-$ $53.5 \%), 29.0 \%$ anxiety features $(95 \% \mathrm{Cl}=14.2-50.3 \%), 26.3 \%$ depressive symptoms $(95 \% \mathrm{Cl}=12.5-$ $47.1 \%), 20.7 \%$ posttraumatic stress disorder features $(95 \% \mathrm{Cl}=13.2-31 \%), 16.1 \%$ somatization $(95 \% \mathrm{Cl}=$ $0.2-96.0 \%)$, and $14.0 \%$ stigmatization feelings $(95 \% \mathrm{Cl}=6.4-28.1 \%)$.

When to comes to the impact of the pandemic on men versus women, despite a higher fatality rate from COVID-19 for men, women reported higher rates of mental health issues with an increased workload due to lockdown and quarantine measures. For example, young professionals, nurses and women reported higher rates of psychological burden in Wuhan at the beginning of the pandemic. In fact, when examining burnout among healthcare workers, the only factor associated with high levels across domain was being female. Another recent review found that being younger, more junior, or being the primary caregiver of a young child increased the risk for psychologist stress among healthcare workers during the pandemic.

Outside of a pandemic, anxiety and depression are the most common mental health diagnoses among individuals in Argentina, the second largest country in Latin America, with 9.4\% experiencing anxiety and $5.7 \%$ reporting depression during a 12-month period. One group of individuals who experience higher rates of mental health difficulties than the general population are healthcare workers. By nature of their work, healthcare workers report higher levels of anxiety, depression, burnout, and twice the rate of suicide compared to the general population. During the pandemic, $54 \%$ of Argentinean healthcare workers reported symptoms related to depression, and $9.1 \%$ reported it as severe; importantly, of those individuals surveyed in this study, $93 \%$ of the workers expressed they did not have any mental health diagnosis prior to pandemic. What remains unknown, is how these self-reported rates of anxiety and depression are impacting healthcare workers ability to continue to do their jobs. The aims of this project are to (1) examine the use of psychiatric leave by Argentinian healthcare workers during the COVID-19 pandemic, as well as to (2) explore if there are differences in psychiatric sick leave use by gender.

\section{Participants And Methods}

\section{Setting}

The Metropolitan Area of Buenos Aires (AMBA) is the common urban area that makes up the Autonomous City of Buenos Aires (CABA) and 40 municipalities of the Province of Buenos Aires, including Vicente Lopez. The municipality of Vicente Lopez is located north of the Autonomous City of Buenos Aires (CABA) and has a population of 270,929 inhabitants (INDEC 2010 census).

\section{Data}


All the data was provided by the Municipal Direction of Occupational Medicine. This Direction routinely and systematically collects all the absenteeism, sick leaves and personal vacations the municipal workers have. For this analysis we focused on psychiatric sick leaves for all the health workers.

\section{Excess of psychiatric sick leave calculation}

We developed an exploratory analysis of "excess of psychiatric sick leave" in health workers at a municipal level for Buenos Aires Province from January to October 2020. For the analysis we used cases of psychiatric sick leave in the same period in the past 5 years (2015-2019) and observed psychiatric sick leave cases in 2020. We report the results in rates per 100 health workers. We performed the analysis for the total psychiatric sick leave and stratified by sex. We analyzed the sick leave rate per whole period and per month. We compared observed rates for the current period with the average expected rate and the higher limit of the $95 \%$ confidence interval (Cl 95\%) derived from the historic mortality rate from five years of data. An Institutional Board (IRB) approved the protocol.

To measure excess psychiatric sick leave during the COVID-19 pandemic, we used:

1. Expected psychiatric sick leave to have occurred on a monthly basis in the same period in the past 5 years (based on historical data), and

2. Psychiatric sick leave that have occurred/observed in the analyzed period

To assess the difference in "excess of psychiatric sick leave" between female and male we determined the difference in proportions for both groups and compared the average expected proportion and the higher limit of the $\mathrm{Cl} 95 \%$ derived from the historic mortality rate from five years of data.

\section{Definitions}

-Sick leave: an absence from work permitted because of illness. All the sick absences are paid ones. Regardless the event itself, each health worker has 90 days per year maximum if they have worked in the Municipality less than 5 years. For workers with more than five years, the total amount of days per year increases to 180 days. When the worker has a family member in charge (children, parents, partner) that time duplicates to 180 days per year and 360 days per year. Psychiatric sick leaves are included in the medical sick leaves.

-Psychiatric sick leave: It is a type of sick leave. Most Occupational Medicine Directions in Argentina label the requested sick leaves into categories, one of them being psychiatric sick leave. For this analysis we used that category. An external or private medical doctor defines a diagnosis and the Occupational Medicine Direction categorize that medical leave into different categories or group of events, one being psychiatric sick leaves.

-Health workers: municipal workers working for the "Secretary of Health and Human Development" of the municipality of Vicente Lopez. 


\section{Results}

\section{Excess of psychiatric sick leave. Total}

Table 1 and Fig. 1 show the analyzed data for psychiatric sick leave rate per 100 health workers for the whole January 2020- October 2020 period. Psychiatric sick leave rate per 100 health workers for the whole period analyzed in 2020 was $1.10 \%$; Historical data, 2015-2019 had an average psychiatric sick leave rate per 100 health workers of 0.42 . The excess of psychiatric sick leave in 2020 for the whole analyzed period compared to historical data was $161.90 \%$ with a significant increase when compared to the historical upper Confidence Interval 95\% (122.97\%). For the analysis per month, we observe all the month, but February had a significant increase in the excess of psychiatric sick leave. The month with the higher percentage of psychiatric sick leave increment when compared to historical data is April, with an increase of $306.25 \%$.

Table 1

Excess of Psychiatric sick leave in health workers historical comparison. Total and per month. Vicente Lopez, Argentina. January- October 2020

\begin{tabular}{|lllll|}
\hline Month & $\begin{array}{l}\text { 2015-2019 Monthly } \\
\text { average X 100 health } \\
\text { workers (95\% Cl) }\end{array}$ & $\begin{array}{l}\text { 2020 Psychiatric sick } \\
\text { leave } 100 \text { health } \\
\text { workers }\end{array}$ & $\begin{array}{l}\text { \% of } \\
\text { increase } \\
\text { above } \\
\text { baseline }\end{array}$ & $\begin{array}{l}\text { \% of increase } \\
\text { above } \\
\text { threshold }\end{array}$ \\
\hline January & $0.38(0.17-0.59)$ & 0.60 & 57.89 & 1.82 \\
\hline February & $0.22(0.05-0.39)$ & 0.30 & 36.36 & -22.80 \\
\hline March & $0.30(0.02-0.58)$ & 0.80 & 166.67 & 38.60 \\
\hline April & $0.32(0.21-0.43)$ & 1.30 & 306.25 & 199.34 \\
\hline May & $0.32(0.15-0.49)$ & 1.20 & 275.00 & 145.60 \\
\hline June & $0.38(0.20-0.56)$ & 1.20 & 215.79 & 114.42 \\
\hline July & $0.72(0.48-0.96)$ & 1.10 & 52.78 & 15.16 \\
\hline August & $0.42(0.19-0.65)$ & 1.50 & 257.14 & 131.88 \\
\hline September & $0.50(0.32-0.68)$ & 2.00 & 300.00 & 196.16 \\
\hline October & $0.50(0.29-0.71)$ & 1.20 & 140.00 & 70.08 \\
\hline Total & $0.42(0.35-0.49)$ & 1.10 & 161.20 & 122.97 \\
\hline
\end{tabular}


Table 2 and Fig. 2 show monthly psychiatric sick leave rate stratified by sex of the health workers. For female health workers, and for the whole period, the Psychiatric sick leave rate per 100 health workers in 2020 was almost 1.3\%; Historical data, 2015-2019 had an average psychiatric sick leave rate per 100 female health workers of 0.53 . The excess of psychiatric sick leave in 2020 for the whole analyzed period compared to historical data was $137.8 \%$ with a significant increase when compared to the historical upper Confidence Interval 95\% (98.8\%). All the months but February and July, show a significant increase of psychiatric sick leaves. The month with the higher significant increase was September with a 345.3\% increase compared to historical data. Male health workers showed in the entire period, a Psychiatric sick leave rate per 100 health workers in 2020 of $0.70 \%$; Historical data, 2015-2019 had an average psychiatric sick leave rate per 100 male health workers of 0.17 . The excess of psychiatric sick leave in 2020 for the whole analyzed period compared to historical data was almost $307 \%$ with a significant increase when compared to the historical upper Confidence Interval 95\% (152.9\%). All the months but January and February, show a significant increase of psychiatric sick leaves. The month with the higher significant increase was May with an increase of almost $910 \%$. 
Table 2

Excess of Psychiatric sick leave in health workers historical comparison. Total and per month and per sex. Vicente Lopez, Argentina. January- October 2020

\begin{tabular}{|c|c|c|c|c|c|}
\hline Sex & Month & $\begin{array}{l}2015-2019 \text { Monthly } \\
\text { average X100 health } \\
\text { workers }(95 \% \mathrm{Cl})\end{array}$ & $\begin{array}{l}2020 \text { Psychiatric } \\
\text { sick leave x } 100 \\
\text { health workers }\end{array}$ & $\begin{array}{l}\% \text { of } \\
\text { increase } \\
\text { above } \\
\text { baseline }\end{array}$ & $\begin{array}{l}\% \text { of } \\
\text { increase } \\
\text { above } \\
\text { threshold }\end{array}$ \\
\hline \multirow[t]{10}{*}{ Female } & January & $0.54(0.24-0.84)$ & 0.86 & 59.85 & 2.87 \\
\hline & February & $0.26(0.06-0.46)$ & 0.43 & 65.38 & -5.84 \\
\hline & March & $0.43(0.07-0.79)$ & 0.99 & 132.39 & 26.07 \\
\hline & April & $0.41(0.25-0.58)$ & 1.41 & 240.58 & 143.23 \\
\hline & May & $0.45(0.21-0.70)$ & 1.4 & 209.73 & 101.20 \\
\hline & June & $0.53(0.20-0.87)$ & 1.26 & 136.84 & 45.64 \\
\hline & July & $0.96(0.57-1.36)$ & 1.25 & 29.94 & -7.97 \\
\hline & August & $0.57(0.28-0.86)$ & 1.81 & 218.66 & 110.31 \\
\hline & September & $0.53(0.43-0.63)$ & 2.36 & 345.28 & 276.15 \\
\hline & October & $0.68(0.43-0.64)$ & 0.97 & 43.07 & 3.42 \\
\hline \multicolumn{2}{|c|}{ Total female } & $0.53(0.43-0.64)$ & 1.27 & 137.83 & 98.77 \\
\hline \multirow[t]{10}{*}{ Male } & January & $0.07(-0.06-0.19)$ & 0.00 & -100.00 & -100.00 \\
\hline & February & $0.13(-0.03-0.30)$ & 0.00 & -100.00 & -100.00 \\
\hline & March & $0.07(-0.07-0.20)$ & 0.34 & 400.00 & 68.92 \\
\hline & April & $0.20(0.04-0.35)$ & 1.02 & 418.43 & 187.88 \\
\hline & May & $0.07(-0.06-0.20)$ & 0.68 & 909.80 & 241.15 \\
\hline & June & $0.13(-0.03-0.30)$ & 1.01 & 676.94 & 253.09 \\
\hline & July & $0.27(0.02-0.51)$ & 0.66 & 146.09 & 28.28 \\
\hline & August & $0.14(-0.03-0.30)$ & 0.66 & 383.65 & 119.82 \\
\hline & September & $0.46(0.02-0.91)$ & 0.98 & 112.18 & 8.25 \\
\hline & October & $0.20(-0.06-0.47)$ & 1.63 & 706.03 & 248.18 \\
\hline \multicolumn{2}{|c|}{ Total male } & $0.17(0.07-0.28)$ & 0.70 & 306.98 & 152.97 \\
\hline
\end{tabular}


Table 3 and Fig. 3. When analyzing the differences in proportion of psychiatric sick leave per sex of health workers we observe a significant difference when comparing female to male for the whole analyzed period; An increase in the differences in proportion per sex in 2020 of $59.34 \%$ when compared to historical data and a significant increase when compared to the historical upper Confidence Interval 95\% (22.93\%). The significant difference in proportion is driven by January, February, March, May, August and September. The rest of the month shows no significant difference. The month with higher significant increase was September. October shows a flip in the direction of the differences, meaning the proportion of psychiatric sick leave in males is higher than in females.

Table 3

Difference per sex in proportion of psychiatric sick leaves in health workers. historical comparison. Total and per month. Vicente Lopez, Argentina. January- October 2020

\begin{tabular}{|lllll|}
\hline Month & $\begin{array}{l}\text { 2015-2019 } \\
\text { difference in } \\
\text { proportion. }\end{array}$ & $\begin{array}{l}\text { 2020 difference in } \\
\text { proportion X 100 } \\
\text { Monthly average } \\
\text { X100 (95\% Cl) }\end{array}$ & $\begin{array}{l}\text { \% of increase } \\
\text { above baseline }\end{array}$ & $\begin{array}{l}\text { \% of increase } \\
\text { above threshold }\end{array}$ \\
\hline January & $0.47(0.16-0.78)$ & 0.86 & 82.20 & 10.19 \\
\hline February & $0.13(-0.08-0.33)$ & 0.43 & 241.27 & 28.73 \\
\hline March & $0.36(0.10-0.62)$ & 0.66 & 84.36 & 6.67 \\
\hline April & $0.22(0.00-0.43)$ & 0.39 & 80.56 & -9.89 \\
\hline May & $0.39(0.08-0.69)$ & 0.72 & 86.53 & 3.91 \\
\hline June & $0.40(-0.08-0.88)$ & 0.25 & -37.81 & -71.62 \\
\hline July & $0.69(0.13-1.25)$ & 0.59 & -14.99 & -52.92 \\
\hline August & $0.43(0.17-0.70)$ & 1.15 & 164.98 & 63.90 \\
\hline September & $0.07(-0.38-0.51)$ & 1.38 & 1990.91 & 169.02 \\
\hline October & $0.48(-0.14-0.81)$ & -0.66 & -238.66 & -181.29 \\
\hline Total & $0.36(0.26-0.47)$ & 0.58 & 59.34 & 22.93 \\
\hline
\end{tabular}

\section{Discussion}

In line with recent findings of increased anxiety and depression in healthcare workers, , this study found healthcare workers in the Argentinian municipality of Vicente Lopez used a significantly higher number of psychiatric sick leave during the first eight months of COVID-19 pandemic, with the largest increase 
occurring in April 2020, when uncertainty surrounding COVID-19 was at its highest globally. Similarly to other outbreaks such as SARS in 2003, the uncertainty surrounding COVID-19 including lack of information about transmission, treatment, or mortality rates likely led to healthcare workers feeling higher rates of stress, leading to them utilizing psychiatric sick leave.

A number of different factors impacted providers' use of psychiatric leave differentially, such as the higher rates of psychiatric sick leave used by female healthcare workers compared to their male counterparts. These replicate findings of personal and work-related burnout as well as higher rates of reported psychological symptoms in female healthcare workers. It is possible that, due to traditional gender roles, these female healthcare workers may have been primarily responsible for childcare as well as elder care, which may have increased their levels of stress and resulted in more psychiatric sick leave being used. Parenting responsibilities have been reported as stressors during the current COVID-19 pandemic, as well as in the SARS outbreak in 2003. Alternatively, it is also possible that impact of masculinity on healthcare avoidance may have resulted in men using similar amount of leave, but labeling it differently compared to their female counterparts, .

Increased used of either general and psychiatric sick leave reflect challenges experienced by healthcare workers individually, and for the healthcare system as a whole. On an individual level, while removing the overall stressor of the pandemic is impossible, there are interventions for anxiety and depression, particularly during crises, such as Psychological First Aid and Skills for Psychological Recovery, that could result in fewer days used in the long-term as healthcare workers develop skills to help cope with the increased stress. For healthcare teams, increases in sick leave mean staff shortages during peak-capacity times, resulting in increased demand and unplanned shifts for the workers there. This increased burden can then increase the risk of that individual needing their own leave in the future, continuing to leave the team short-staffed. Relatedly, without intervention, systems can begin to buckle under the weight of an overburdened healthcare force. There are a number of potential interventions healthcare systems could implement to aid healthcare workers. Telehealth, for example, has increased during the pandemic to approximately 1 billion appointments a year, compared to the originally projected 36 million appointments prior to COVID-19 (Coombs, 2020). Strategic use of telehealth appointments, both for outpatient appointments that can be conducted via telehealth fairly easily (e.g., mental health appointments) as well as to triage care via telehealth from overstretched hospitals in a virus hotspot to other facilities would allow for more even work flow, and may prevent healthcare workers from feeling burnout as rapidly. Additionally, allowing providers to telework from home when possible could result in lower levels of anxiety related virus exposure.

This study has a number of limitations important to consider when interpreting the results. First, many countries do not have different categories of leave, preventing comparison of our results with samples internationally. Even with the categorizing of psychiatric versus general leave in our sample, we do not know the individual episodes or diagnoses associated with the use of the leave. Within this sample, we also do not know which hospitals or units these healthcare workers were associated with or the level of exposure of patients with COVID-19, preventing us from looking at the direction relationship between 
caring for individuals with COVID-19 and the use of healthcare worker psychiatric leave. Lastly, age of the healthcare workers was not available for this project. As other projects have found that younger

healthcare workers have reported higher rates of mental health problems during the pandemic ${ }^{26}$, this would have been interesting to replicate in our sample.

Despite these limitations, this study adds important information about how healthcare workers have been responding to the COVID-19 pandemic. As expected, healthcare workers utilized higher rates of psychiatric leave while struggling with increased stress as a result of personal, institutional, and global factors. For healthcare workers that experience stress, individual interventions such as Psychological First Aid could provide coping skills. However, beyond the individual level, there are a number of system changes a healthcare system could make, including using telehealth as a way to reduce burden on overstretched hospitals as well as for anxious healthcare providers, resulting fewer days of psychiatric leave being taken.

\section{Future proposals}

Data shows a flip in October, the difference within sexes, towards male health workers. It would be interesting to see if this pattern continues in the following months till the end of 2020 and the beginning of 2021.

\section{Declarations}

\section{Ethics Considerations and Disclosure}

The principles outlined in the Declaration of Helsinki have been followed. This is a Quality Improvement (QI). This project does not involve human subjects as defined under 45 CFR 46.102(e)

\section{Consent for publication}

No identifiable data was utilized in this analysis.

\section{Availability of data and materials}

The datasets used and analyzed during the current study are obtained from the Municipal Direction of Occupational Medicine.

\section{Competing interests}

The authors declare that they have no competing interests. 


\section{Funding}

This proposal received no funding.

\section{Authors' contributions}

AMM: design, data analysis, creation of models, application of statistical analysis

USM: drafted the proposal revised every version, formulation of overarching research goals and aims

AMR: data collection, writing the proposal, preparation, and review of the manuscript

IJF: drafted the proposal revised every version, data analysis.

RZ: design, data analysis, data formatting, application of statistical analysis.

\section{Acknowledgements}

Enrique Vazquez Fernandez. M.D, PHD

\section{References}

1. Pfefferbaum B, North CS. Mental Health and the Covid-19 Pandemic. New England Journal of Medicine. 2020;383(6):510-2.

2. Egede LE, Ruggiero KJ, Frueh BC. Ensuring mental health access for vulnerable populations in COVID era. J Psychiatr Res. 2020; 129:147-148. doi: 10.1016/j.jpsychires.2020.07.011.

3. The Lancet Infectious Diseases. The intersection of COVID-19 and mental health. The Lancet Infectious Diseases. 2020;20(11):1217.

4. Greenberg N, Docherty M, Gnanapragasam S, Wessely S. Managing mental health challenges faced by healthcare workers during covid-19 pandemic. BMJ. 2020 Mar 26;368:m1211. doi:

10.1136/bmj.m1211. PMID: 32217624.

5. Williamson V, Murphy D, Greenberg N. COVID-19 and experiences of moral injury in front-line key workers. Occupational Medicine. $2020 \mathrm{Jul}$ 17;70(5):317-9.

6. Huang JZ, Han MF, Luo TD, Ren AK, Zhou XP. [Mental health survey of medical staff in a tertiary infectious disease hospital for COVID-19]. Zhonghua lao Dong wei Sheng zhi ye Bing za zhi = Zhonghua Laodong Weisheng Zhiyebing Zazhi = Chinese Journal of Industrial Hygiene and Occupational Diseases. 2020 Mar;38(3):192-195. DOI: 10.3760/cma.j.cn121094-20200219-00063.

7. Chirico, F., Nucera, G., \& Magnavita, N. (2020). Protecting the mental health of healthcare workers during the COVID-19 emergency. BJPsych International, 1-2. doi:10.1192/bji.2020.39. 
8. Zhang W, Wang K, Yin L, Zhao W, Xue Q, Peng M, Min B, Tian Q, Leng H, Du J, Chang H, Yang Y, Li W, Shangguan F, Yan T, Dong H, Han Y, Wang Y, Cosci F, Wang H: Mental Health and Psychosocial Problems of Medical Health Workers during the COVID-19 Epidemic in China. Psychother Psychosom 2020; 89:242-250. doi: 10.1159/000507639.

9. Pablo GS de, Vaquerizo-Serrano J, Catalan A, Arango C, Moreno C, Ferre F, et al. Impact of coronavirus syndromes on physical and mental health of health care workers: Systematic review and meta-analysis. Journal of Affective Disorders. 2020; 275:48-57.

10. Thibaut F, van Wijngaarden-Cremers PJM. Women's Mental Health in the Time of Covid-19 Pandemic. Frontiers in Global Women's Health. 2020;1:17.

11. Lai J, Ma S, Wang Y, Cai Z, Hu J, Wei N, et al. Factors Associated with Mental Health Outcomes Among Health Care Workers Exposed to Coronavirus Disease 2019. JAMA Network Open. 2020 Mar 23;3(3): e203976-e203976.

12. Jalili M, Niroomand M, Hadavand F, Zeinali K, Fotouhi A. Burnout among healthcare professionals during COVID-19 pandemic: a cross-sectional study. medRxiv. 2020 Jan 1;2020.06.12.20129650. https://doi.org/10.1101/2020.06.12.20129650

13. Kisely S, Warren N, McMahon L, Dalais C, Henry I, Siskind D et al. Occurrence, prevention, and management of the psychological effects of emerging virus outbreaks on healthcare workers: rapid review and meta-analysis BMJ 2020; 369 :m1642 doi:10.1136/bmj.m1642

14. Stagnaro, J.C., Cía, A.H., Aguilar Gaxiola, S. et al. Twelve-month prevalence rates of mental disorders and service use in the Argentinean Study of Mental Health Epidemiology. Soc Psychiatry Psychiatr Epidemiol 53, 121-129 (2018).https://doi.org/10.1007/s00127-017-1475-9

15. Andrew, L. B., \& Brenner, B. E. (2015). Physician suicide. Medscape Drugs Dis, 17.

16. RASIC - Red Argentina de Salud Integral y Cuidados Factores estresores y protectores en las personas trabajadoras de la Salud: investigación internacional multicéntrica. - 1a ed. -Rawson: Universidad del Chubut, 2020. Libro digital, PDF - (Investigaciones UDC. Salud Mental, cuidados y trabajo; 1) Archivo Digital: descarga y online ISBN 978-987-46148-5-8

17. INSTITUTO NACIONAL DE ESTADISTICA Y CENSOS. REPUBLICA ARGENTINA. CENSO 2010.https://www.indec.gob.ar/indec/web/Nivel4-Tema-2-41-135

18. Chen, J., Liu, X., Wang, D. et al. Risk factors for depression and anxiety in healthcare workers deployed during the COVID-19 outbreak in China. Soc Psychiatry Psychiatr Epidemiol 56, 47-55 (2021).https://doi.org/10.1007/s00127-020-01954-1

19. Serrano-Ripoll MJ, Meneses-Echavez JF, Ricci-Cabello I, Fraile-Navarro D, Fiol-deRoque MA, PastorMoreno G, et al. Impact of viral epidemic outbreaks on mental health of healthcare workers: a rapid systematic review and meta-analysis. Journal of Affective Disorders. 2020 Dec 1; 277:347-57.

20. Maunder R. The experience of the 2003 SARS outbreak as a traumatic stress among frontline healthcare workers in Toronto: lessons learned. Philos Trans R Soc Lond B Biol Sci. 2004;359(1447):1117-1125. doi:10.1098/rstb.2004.1483 
21. Khasne RW, Dhakulkar BS, Mahajan HC, Kulkarni AP. Burnout among Healthcare Workers during COVID-19 Pandemic in India: Results of a Questionnaire-based Survey. Indian J Crit Care Med. 2020;24(8):664-671. doi:10.5005/jp-journals-10071-23518

22. Vizheh M, Qorbani M, Arzaghi SM, Muhidin S, Javanmard Z, Esmaeili M. The mental health of healthcare workers in the COVID-19 pandemic: A systematic review [published online ahead of print, 2020 Oct 26]. J Diabetes Metab Disord. 2020;1-12. doi:10.1007/s40200-020-00643-9.

23. Lee SJ, Ward KP, Chang OD, Downing KM. Parenting activities and the transition to home-based education during the COVID-19 pandemic. Children and Youth Services Review. 2021; 122:105585.

24. Spinelli M, Lionetti F, Pastore M, Fasolo M. Parents' Stress and Children's Psychological Problems in Families Facing the COVID-19 Outbreak in Italy. Frontiers in Psychology. 2020; 11:1713.

25. DiGiovanni C, Conley J, Chiu D, Zaborski J. Factors influencing compliance with quarantine in Toronto during the 2003 SARS outbreak. Biosecur Bioterror. 2004;2(4):265-72. doi: 10.1089/bsp.2004.2.265. PMID: 15650436.

26. Himmelstein MS, Sanchez DT. Masculinity impediments: Internalized masculinity contributes to healthcare avoidance in men and women. Journal of Health Psychology. 2016;21(7):1283-1292. doi:10.1177/1359105314551623

27. Geiger-Brown J, Rogers VE, Trinkoff AM, Kane RL, Bausell RB, Scharf SM. Sleep, sleepiness, fatigue, and performance of 12-hour-shift nurses. Chronobiol Int. 2012 Mar;29(2):211-9. doi: 10.3109/07420528.2011.645752. Erratum in: Chronobiol Int. 2012 Aug;29(7):961. PMID: 22324559.

\section{Figures}

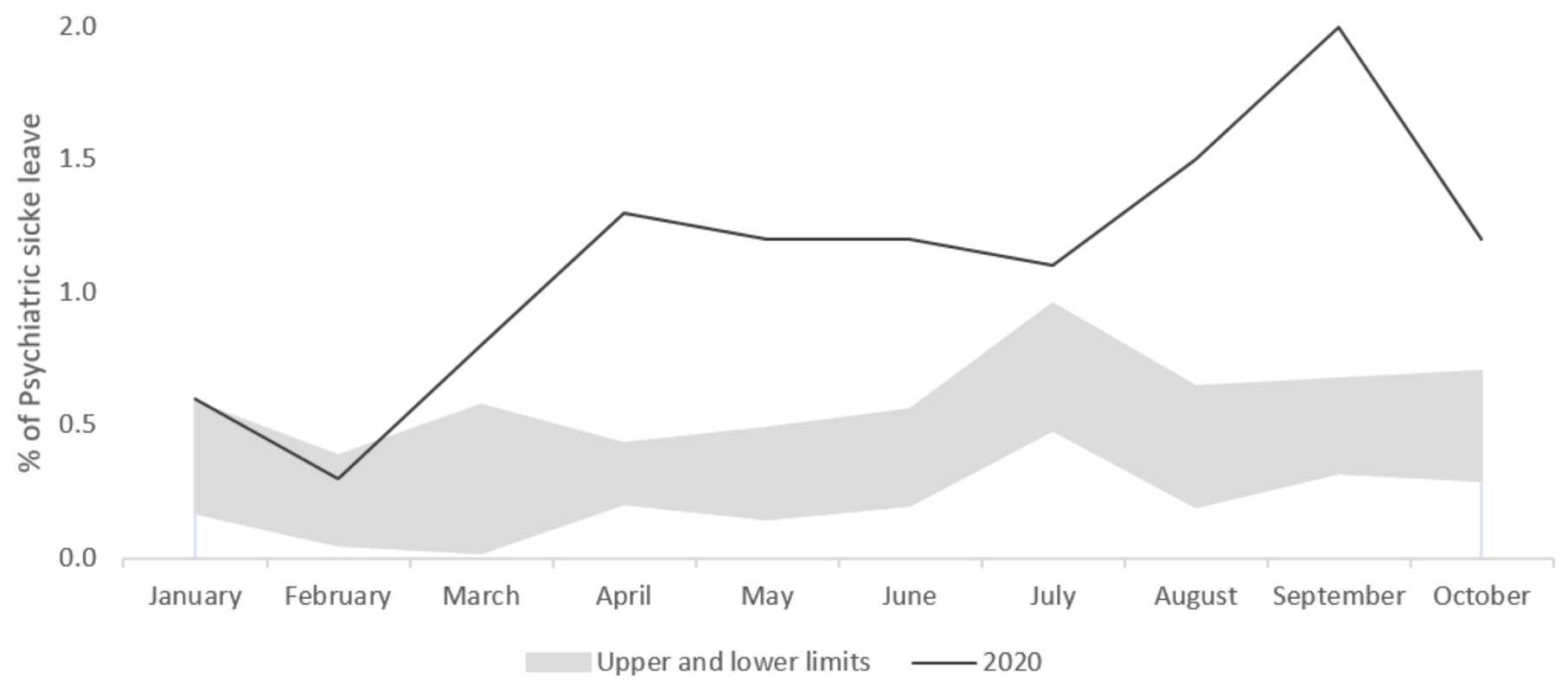

\section{Figure 1}


Psychiatric sick leaves in health workers, Total sample per month. 2015-2019 upper and lower 95\% Cl vs 2020. Vicente Lopez, Argentina. January- October.

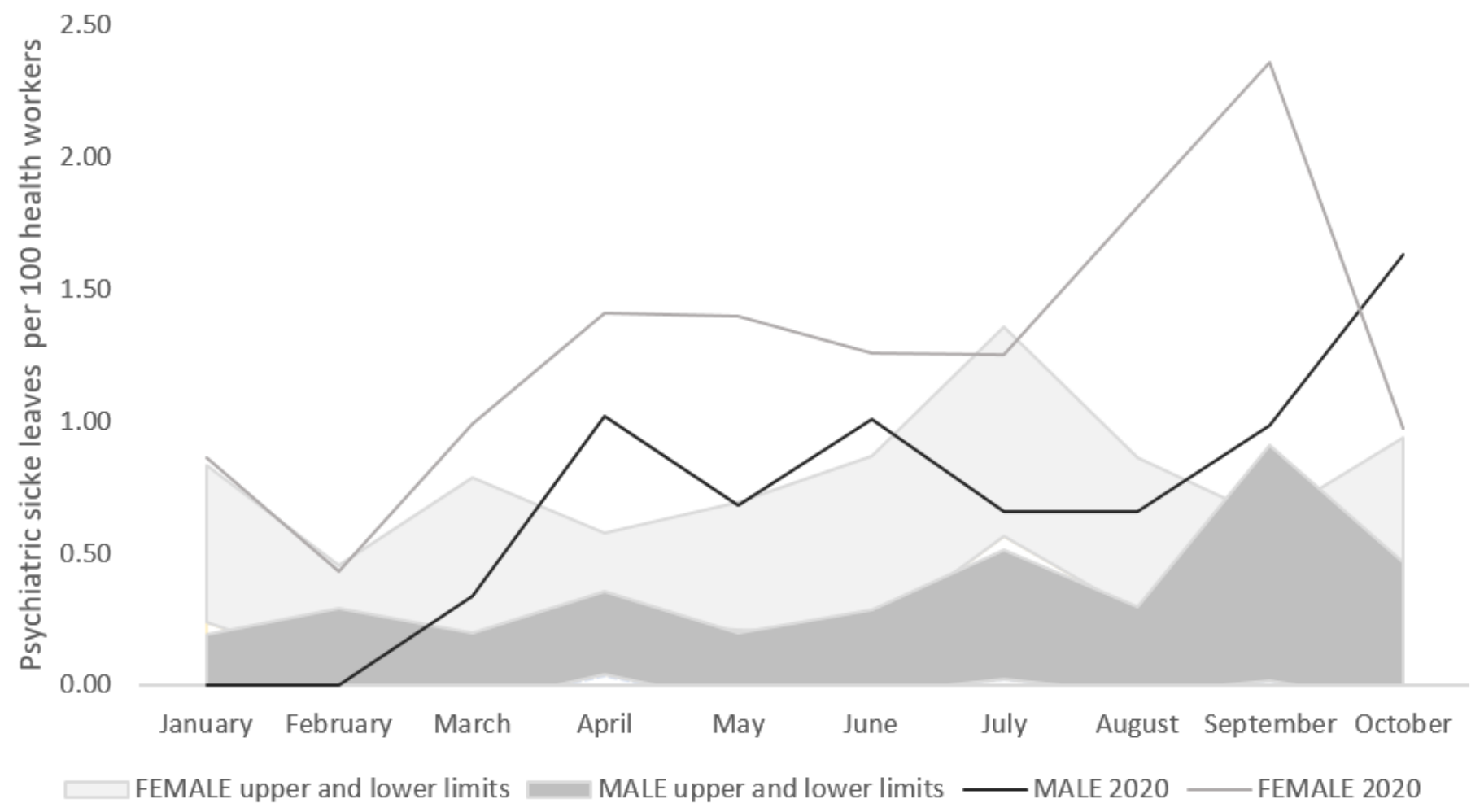

\section{Figure 2}

Psychiatric sick leaves in Health Workers per sex and month. 2015- 2019 upper and lower limits 95\% $\mathrm{Cl}$ vs 2020. Vicente Lopez, Argentina. January- October.

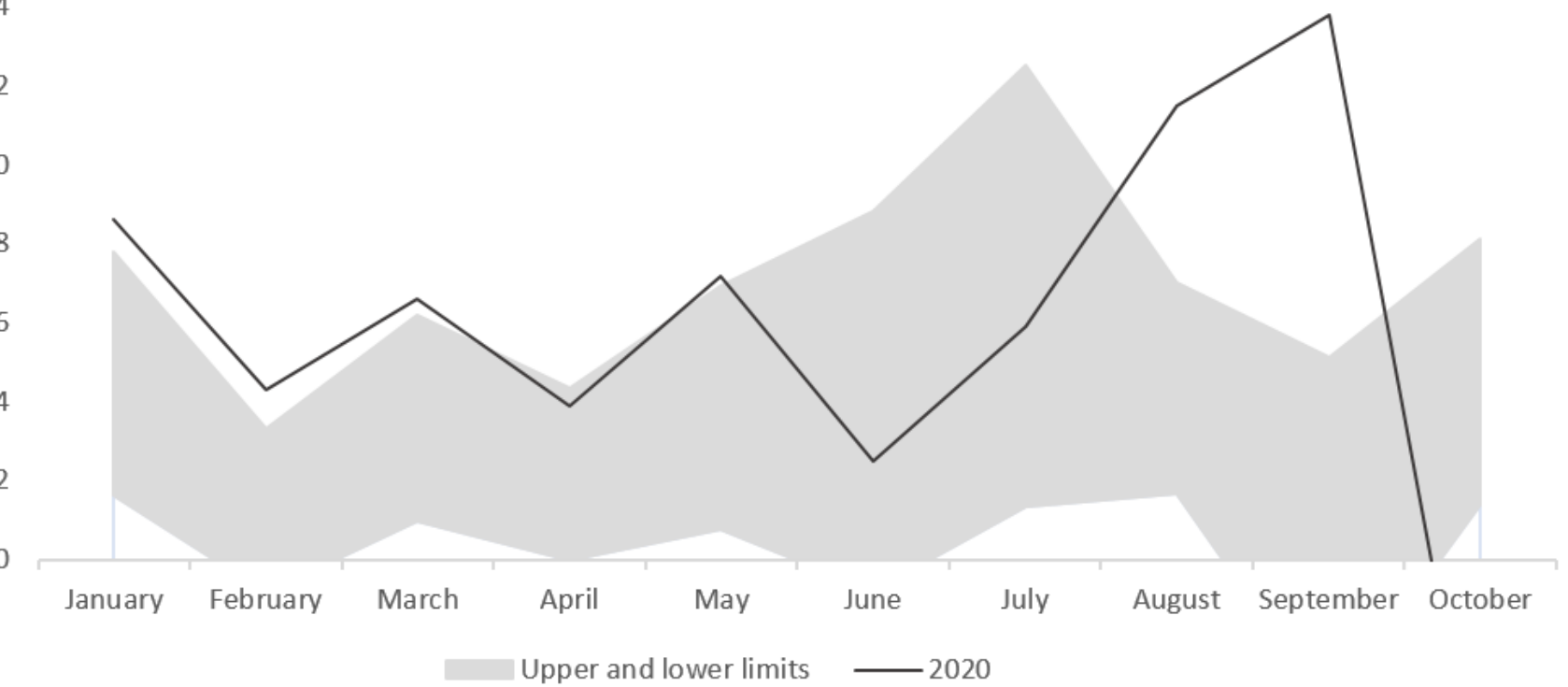




\section{Figure 3}

Difference in percentage of psychiatric sick leaves female- male Health Workers, 2015-2019 upper and lower limits $95 \% \mathrm{Cl}$ vs 2020 . Vicente Lopez, Argentina. January- October. 